\title{
Paradojas de la domesticación: aproximaciones a la relación problemática entre tecnología, libertad y eugenesia
}

\section{Sascha Miguel Cornejo Puschner}

https://orcid.org/0000-0002-9377-6814

Instituto de investigación IRITHESyS, HU, Berlín

scornejopuschner@gmail.com

RESUMEN

El desarrollo tecnológico de las últimas décadas ha suscitado la exigencia de establecer límites más precisos a su intervención en los cuerpos orgánicos. Desde diversos ámbitos de las ciencias sociales y la filosofia política se ha problematizado este campo abierto a la intervención y apropiación de los componentes moleculares y genéticos a partir de cada vez más relajadas normativas legales. Este artículo nace a partir de cierta trayectoria de análisis teórico del campo de la biopolítica y las STS con la intención de aportar algunos elementos reflexivos a este debate sobre la relación ser humano y tecnología. La tesis que se intenta defender es el carácter abierto y maleable de la constitución humana, no como un aspecto deseable en sí, sino más bien como expresión de una lectura realista de los procesos ya iniciados por la intervención tecnológica en los cuerpos humanos.

Palabras clave: eugenesia, domesticación, tecnología, antropotécnicas, libertad, naturaleza humana. 


\title{
Paradoxes of domestication: approximations to the problematic rela- tionship between freedom and eugenics
}

\author{
ABSTRACT
}

During the last decade, technological development has brought the need of setting precise boundaries regarded to organic bodies. Diverse perspectives coming from Social Sciences and Political Philosophy have problematized/questioned this latter, which has been loosely regulated by legal norms, in relation to the appropriation of molecular and genetic components. However, a broad debate about the dangers of Biotechnology and its transformational power has arisen. The practice of this science and the new ethical and axiological requirements demanded to frame the intervention of technology, in organic human processes.

This article aims at contributing with a number of critical perspectives to this theoretical debate.

Keywords: Eugenics, domestication, technology, anthropo technique, freedom, human nature. 


\section{INTRODUCCIÓN: ¿DOMESTICAR A TRAVÉS DE LA TECNOLOGÍA?}

En estos tiempos, la tecnología estrecha cada vez más lazos con nuestra constitución y conformación como seres humanos; por ello, plantearse la pregunta por la domesticación es preguntar por lo que nos hace humanos. Una pregunta que se vuelve cada vez más compleja, debido que los imperativos tecnológicos han transformado el margen de acción aplicado a nuestra propia «humanidad». Ante los intersticios abiertos por la manipulación tecnológica ya no es tan simple ni obvio lo que entendemos por ser humano. El mundo tal como lo conocemos $y$ enfrentamos se ha ido conformando en una serie de entrelazamientos entre humanos y no humanos, tecnología, semióticas, ontologías diversas: cuasiobjetos y cuasisujetos pueblan el mundo desde sus propias indefiniciones (Latour, 2005; 2007). De acuerdo a esta lectura, la tecnología es un caso paradigmático de indefinición: ¿en qué plano podemos situar la serie de combinaciones entre «tecnología» y «naturaleza», los innumerables entes híbridos que hoy son parte ya de la historia de las tecnociencias? Sin duda que estos nos ponen en aprietos, ya que la tecnología y sus productos se sustraen a nuestras categorías de pensamiento «clásicas» que nos permitían distribuir en uno u otro plano ontológico las diversas manifestaciones de la actividad o inactividad humana relativos a la naturaleza o a la cultura. De acuerdo con lo anterior, lo que se interroga en este artículo es justamente esa zona de indefinición producida por una perfomance tecnológica ${ }^{1}$ cuyos contornos se vuelven aún más difusos tratándose de la manipulación tecnológica del ser humano, su potencial eugenésico, o, en otras palabras, su «potencial domesticador».

Concibiendo una separación entre lo que el ser humano «hace» y lo que «dice que hace», al respecto «performance» remite aquí a una praxis de tipo tecnológica y su relativa indiferencia de lo que ocurra en el ámbito de las definiciones que hacemos de ella o sus productos. 
¿Pero qué significa «domesticar»? Esta palabra sin duda tiene ciertas afinidades semánticas con «cultivar», y según la definición de la RAE una de sus acepciones quiere decir «modelar el carácter de alguien». De ahí que la pregunta por la domesticación integra el vasto campo de la filosofía biopolítica, cuando se enfrenta a la pregunta por la conducción de los seres humanos que viven en sociedad ${ }^{2}$.

En gran parte esta pregunta estaba presente cuando el filósofo alemán Peter Sloterdijk la encaró en una conferencia titulada Normas para el parque humano en el año 1999, a propósito de la Carta sobre el humanismo de Heidegger más allá de la distinción naturaleza y cultura. En su lectura Sloterdijk menciona una idea un tanto ambigua, antropotécnicas ${ }^{3}$, concepto que sugiere que el carácter transformador de la energía humana no únicamente se yergue sobre el mundo que lo rodea, sino sobre todo a sí mismo. En este sentido, la transformación del mundo implicaba, a su vez, la transformación del propio ser humano. Sin duda que esto merece cuestionamientos, cuando el ser humano se convierte en la fuerza superior que tiende transformar o también violentar su propia constitución.

Interrogar la idea de la domesticación del ser humano por medio de la tecnología implica la emergencia de una ontología que tome a esta por objeto y que posibilite otras lecturas más allá de la ya clásica distinción entre naturaleza y cultura, aun firmemente arraigada en nuestro ideario occidental, y alejada así de las reiteradas visiones apologéticas como detractoras. Sloterdijk, lejos de compartir el pesimismo cultural a lo Adorno y Horkheimer, o más tarde con las ideas del

2 No es casualidad la inferencia de Foucault al considerar las tecnologías de poder, desde el psiquiátrico, los hospitales y cárceles, en su estrecha vinculación con una esfera más amplia conformada a partir de una «tecnología política». En Foucault los límites entre una disciplina - como saber instaurado - y una tecnología — no entendida únicamente como «materialidad»-, se tornan borrosas. La famosa unión semántica entre saber-poder, también puede ser expresada como tecnología-política-saber.

3 En uno de los pasajes del texto Sloterdijk se sostiene: «Es el signo de los tiempos de la técnica y la antropotécnica que, cada vez más, los hombres van a parar por casualidad a la parte activa o subjetiva de la selección, incluso sin haber tenido que esforzarse intencionadamente por alcanzar el papel del seleccionador. Cabe además afirmar lo siguiente: existe un malestar en el poder de elegir, y pronto llegará a ser admisible como opción por la inocencia que los hombres se nieguen explícitamente a ejercer el poder de selección después de haber luchado realmente por conseguirlo» (Sloterdijk, 2006, p. 70). Dentro del contexto de la reflexión sobre el humanismo, y recogiendo cierta tradición de reflexión heideggeriana que recuerda la paradojal situación humana ante un poder devastador como es el de la bomba atómica, la lucha del ser humano por alcanzar cierto poder y dominio sobre las fuerzas de la naturaleza no parecen estar exentas de conflictividades no solo éticas sino también políticas. Estas configuran gran parte de las discusiones actuales que intentan limitar el poder desatado por la ciencia y la tecnología. 
propio Habermas, se sitúa en un terreno apartado de una crítica a la tecnología como nueva forma de control y dominio sobre la naturaleza y a través de ella a los seres humanos (Habermas, 1997; Marcuse, 1970) ${ }^{4}$, tópico frecuente en la historia de la escuela de Frankfurt ${ }^{5}$. El particular interés de este filósofo queda expresado en uno de los pasajes más polémicos de la referida lectura:

Cuestiones como si el desarrollo a largo plazo también conducirá a una reforma genética de las propiedades del género; si se abre paso a una futura antropotécniea orientada a la planificación explícita de las características; o si se podrá realizar y extender por todo el género humano el paso del fatalismo natal al nacimiento opcional y a la selección prenatal; son preguntas en las que el horizonte evolutivo, si bien aún nebuloso y nada seguro, comienza a despejarse ante nosotros (Sloterdijk, 2006, pp. 71-72).

Pero las valoraciones morales y éticas acerca de las técnicas de diagnóstico prenatal y preimplantacional pueden resultar ser ambiguas, porque, por un lado acarrean el rechazo sobre ciertos tipos de intervención técnica sobre la vida y en especial sobre la vida humana, pero en términos de selección son considerados aplicaciones necesarias para resguardar la salud de futuros-potenciales-sereshumanos merecedores de vivir una vida «digna», es decir, gozar de plena salud $\mathrm{y}$ facultades físicas y psicológicas. Esto se manifiesta sobre todo en la nueva ideología de la paternidad planificada que se sirve de los viejos argumentos malthusianos para fundamentar la necesidad del control «de calidad» de la población humana a escala global. Además, demuestra que los límites entre una eugenesia «negativa» — según la definición de Francis Galton ${ }^{6}$ —, es decir, la

4 Las simpatías de Sloterdijk con la teoría marxista no es muy grande, esto queda en evidencia sobre todo en su libro Zorn und Zeit (2008) donde el autor desarrolla la idea delos grandes movimientos políticos y también religiosos como «bancos de ira» que capitalizan el resentimiento en pos de profundos cambios políticos y sociales.

5 Esto es importante mencionarlo debido a la aparente visión apologética que sostiene Sloterdijk ante el desarrollo tecnológico, que no sin cierta valentía, se atrevió a problematizar las posibilidades actuales de aplicación tecnológica, en un país como Alemania. que ha vivido duras lecciones históricas con este tipo de aplicaciones, y por ello - al menos sus intelectuales, investigadores y políticos-, son bastante sensibles a tocar esas fibras que recuerden al intervencionismo nacionalsocialista y su nefasta política eugenésica. El debate referido sobre las antropotécnicas se situaba en un clima político e intelectual de la Alemania a principios de siglo XXI, donde abundaba la discusión sobre los potenciales peligros de la ingeniería genética aplicada al ser humano. Ello da cuenta no solo una profusa bibliografía nacional e internacional sobre el tema, sino también los recurrentes artículos de opinión y análisis en periódicos alemanes como Die Zeit y la Frankfurter Allgemeine Zeitung.

6 Francis Galton (1822-1911) es considerado uno de los fundadores de la eugenesia. Sus primeros estudios sociológicos se enfocaron a la incidencia estadística de ciertos caracteres «talentosos» 
eliminación de enfermedades de origen genético, y una eugenesia «positiva», más bien perfeccionadora y selectiva en la búsqueda de ciertos caracteres deseados, son límites difusos, ya que se encuentran sujetas a diversas interpretaciones y por tanto sus límites de permisibilidad no carecen de cierta arbitrariedad (Speck, 2005; Cornejo, 2017a). Esta ambigüedad entre selección, perfeccionamiento y sanación queda expresada sobre todo en la terapia génica y la conflictividad ética que surge desde sus dos modalidades (somática o molecular) (Hubbard y Wald, 1999).

Pero el concepto de antropotécnica pareciera situarse más allá de las valoraciones éticas y axiológicas. Su contenido más bien se encuentra enmarcado en una filosofía de la cultura y en una inspección crítica de la cultura como «modeladora» de seres humanos, anclados en «sistemas de ejercicios» ${ }^{7}$ (Sloterdijk, 2011). No solo la propia ciencia puede ser entendida como un sistema de ejercicio, sino también el vasto campo de prácticas meditativas, el yoga o la filosofía serán enfocados aquí desde ese punto de vista: es la afirmación que toda cultura forma, cultiva y domestica ${ }^{8}$. Pero en vista a los acontecimientos actuales, la relación entre

de miembros de distinguidas familias inglesas del siglo XIX. Fue además precursor del uso de estadísticas como metodología cuantitativa que sirvió como prueba de «objetividad científica» aplicada en las ciencias sociales. Para quien desee indagar en el ideario sociobiológico de Galton, véase la página dedicada a su memoria: www.galton.org

7 Como sostiene el autor a inicio de Has de cambiar tu vida: «Quien hable de la autoproducción del hombre sin mencionar su configuración en la vida que se ejercita ha errado el tema desde el principio. En consecuencia, hemos de dejar prácticamente en suspenso todo lo que haya sido dicho sobre el hombre como un ser trabajador, para traducirlo en el lenguaje de la ejercitación de la vida, 0 de un comportamiento que se configura y acrecienta a sí mismo. Y no solo el fatigado Homo faber - que objetiviza el mundo según su modo de «hacen»- ha de desocupar el sitio que tenía en el centro de la escena lógica, sino que incluso el Homo religiosus vuelto con ritos subreales hacia el mundo del más allá, deberá aceptar la retirada que se merece. Tanto el hombre trabajador como el creyente son englobados en un concepto general. Ya es tiempo de desenmascarar al hombre como un ser vivo surgido por la repetición. Así como el siglo XIX estuvo, en lo cognitivo, bajo el signo de la producción y el siglo XX bajo el de la reflexividad, el futuro debería ser presentado bajo el signo del ejercicio» (Sloterdijk, 2012, p. 17). En la obra citada, el autor desarrolla profusamente una filosofía del ejercicio a raíz de trabajos de filósofos como Nietzsche, Wittgenstein y Foucault, en quienes cree encontrar diversos modos de expresividad de formaciones antropotécnicas en el sentido de una «Askesis en ejercicio» en cada uno de estos autores, sea bajo la forma de la «voluntad de poder» en Nietzsche, la teoría del «disciplinamiento de los cuerpos» en Foucault, o los «juegos de lenguaje» en Wittgenstein. Sin duda son lecturas sugerentes y problemáticas pero que no carecen de originalidad ni coherencia bajo la hábil pluma retórica de Sloterdijjk.

$8 \quad$ Sloterdijk se basa en Nietzsche y sus reflexiones sobre el Superhombre para dar cuenta un conflicto que atañe la domesticación y los tipos de domesticación que se ve sometido el ser humano: «Este es el conflicto básico postulado por Nietzsche de cualquier futuro: la disputa 
cultura, conocimiento, ejercicio y tecnología se revela problemática, sobre todo ante las posibilidades de la biotecnología y la ingeniería genética.

Pero la tendencia de algunos pensadores actuales es justamente interrogar la íntima relación entre ser humano y tecnología no desde una semántica del dominio y el control político, sino de la convivencia y la inteligibilidad de un mundo cada vez más denso en sus redes informáticas, tecnológicas y semióti$\operatorname{cas}^{9}$ (Latour, 2001; Beck, 2001; Castells, 2001). Por ello, más que emitir juicios normativos sobre los límites de lo éticamente permisible, habrá que fijarse en lo que efectivamente ocurre tanto en los laboratorios como en la vida social de las personas que hoy integran el mundo del llamado antropoceno, de la ingeniería genética y del calentamiento global.

En este sentido, antropotécnicas implica a su vez, la posibilidad de pensar distintos grados de intervención en la esfera del mundo circundante, el medio ambiente o los mismos cuerpos orgánicos. Reconocer el uso de la tecnología como «arte de gobierno», implicaría hablar, más que de dominio sobre una naturaleza dispuesta «ahí afuera», integrada y dominada a través de los dispositivos tecnológicos y científicos humanos, de una conjugación de elementos «naturales» y «culturales» que continuamente confluyen en estos procedimientos. Una gubernabilidad en el sentido propuesto por Foucault (2006), basado en los veloces procesos de transformación de la tecnología como prótesis (Freud) natural-culturales. Esto sin duda ha permitido expandir las facultades humanas hasta espacios insospechables, desde el micro- hasta el macrocosmos, de la cual sin duda las ciencias se han beneficiado de esa relación entre apertura de mundo y tecnología

entre los criadores del hombre en dirección a lo pequeño y los criadores hacia lo grande; podría decirse también: entre los humanistas y los superhumanistas, entre los amigos del hombre y los amigos del superhombre. El emblema del superhombre no representa en las argumentaciones de Nietzsche el sueño de una rápida desinhibición de una evasión en lo animal, como se figuraban los embolados malos lectores de Nietzsche de los años treinta. Esta expresión tampoco simboliza la idea de una cría regresiva del hombre hacia el estatus anterior a la era del animal doméstico y del animal eclesiástico. Cuando Nietzsche habla del superhombre, está pensando, una época que hunde profundamente sus raíces en el presente y va más allá. Él toma la medida de los procesos milenarios anteriores, donde hasta ahora se ha practicado la producción de hombres en virtud de íntimos entrecruzamientos entre la cría, la domesticación y la educación; una empresa que, por lo demás, ha sabido hacerse en gran medida invisible, y que, bajo la máscara de la escuela, lo que tenía verdaderamente por objeto era el proyecto de la domesticación» Sloterdijk (2006, pp. 64-65).

9 Claramente esta visión puede adolecer de cierta falta de compromiso político, cuando ya no es la tecnología la que amenaza «desde afuera» la constitución «natural» humana, que al menos teóricamente, habrá que proteger, sin importar que en la práctica esta constitución ya se ve afectada por múltiples intervenciones. 
(Latour, 1998). Pero ello también exige que una filosofía de la tecnología encare el dualismo naturaleza y cultura aún implícita en nuestra concepción dualista de mundo (Descola, 2004). Porque más allá de la actitud defensiva fundamentada en consideraciones bioéticas, la pregunta no es tanto ¿hasta dónde proyectar las capacidades humanas sin incurrir en la disolución misma de este «ser humano»? Su acento analítico más bien tendría que enfocarse en la práctica humana, fundamento de todo discurso «sobre» lo humano, expresado en otra pregunta: ¿qué es lo que se ha hecho durante todo el tiempo de esta historia, que llamamos «humana» y que implica la constante relación con dispositivos materiales, cognitivos y tecnológicos?» ${ }^{10}$. Sin duda que esta preocupación muy presente en Sloterdijk, la de la casa común - el globo, la esfera, el planeta-hogar-, alberga algo más que la clásica preocupación por un sujeto en vías de auto determinación, sino más bien, una fenomenología-en-red, que integra al ser humano a complejos dispositivos semióticos y tecnológicos en la conformación «común» de esa casa que es nuestro planeta y los dispositivos materiales e inmateriales que adquieren cada vez más relevancia. Sin duda un planteamiento problemático que exige ser interrogado a propósito de la eugenesia y sus nuevas expresiones.

\section{TRANSFORMACIÓN DEL SER HUMANO MEDIANTE EUGENESIA}

Hablar hoy de eugenesia irremediablemente nos remite a una época histórica donde la preocupación médica de la salud pública era un asunto de política pública. Esta suerte de politización de la medicina, motivó las políticas de control migratorio, salud pública, salud hereditaria, etcétera, dispositivos biopolíticos claramente asociados a políticas racistas que hoy parecen haber perdido no solo la aceptación pública, sino, sobre todo, legitimidad científica ${ }^{11}$. ¿Qué pasó con esa

10 Me atrevo a afirmar que en este sentido los trabajos de Sloterdijk tienen particulares afinidades con los trabajos de Bruno Latour. Latour también defiende otro punto de vista - menos convencional - acerca de la tecnología como integrada e integradora de los propios procesos sociales. Una vasta semiótica híbrida, da cuenta de este intento comprensivo más allá de las separaciones modernas de naturaleza y cultura (Latour, 1998; 2001).

11 Hoy el concepto de raza ya no es una categoría analítica validada en término científicos, ni en los estudios de genética humana o en antropología. Lo interesante es constatar la gran difusión y amplia aceptación que este término gozaba en los círculos académicos en los siglos XIX y primera mitad del siglo XX. Para una discusión histórica sobre la implicancia de la eugenesia en los países latinoamericanos, en especial en Chile, véase el trabajo historiográfico, editado por César Leyton, Cristián Palacios y Marcelo Sánchez: El bulevard de los pobres. Racismo científico, higiene y eugenesia en Chile e Iberoamérica, siglos XIX y XX. 
determinada visión de mundo que imaginaba (y hoy su carácter «fantasmático» es más que evidente), un mundo ordenado jerárquicamente en una escala valorativa según ciertas características (in)deseadas y determinado por una «naturaleza humana» irremediablemente fija e inmutable? Claramente el concepto de raza se anclaba en una concepción de la naturaleza humana, que no tenía posibilidad de escapar a los designios de su propia inmutabilidad. Más que una «categoría analítica», la idea de raza se apoyó en una «filosofía del destino» basada en una amplia gama de diferenciación de los seres humanos como entes discretos, pero a la vez unidos por la inevitabilidad de la sangre: la herencia. Durante el siglo XIX, la eugenesia perseguía el control de la herencia — sea en su forma negativa o positiva estimada por Galton y sus innumerables seguidores - convirtiéndose en símbolo de progresismo político unido al incipiente positivismo científico que tomaba como auxiliar las valoraciones estadísticas y la consecuente construcción de una norma sociológica, apoyada empíricamente en los comportamientos sociales «normales» $\mathrm{O}$ «desviados» ${ }^{12}$.

La eugenesia como tecnología de control biopolítico, implicaba la normalización de los seres humanos integrados en un nuevo cálculo sociológico. Sin duda, su idea fuerza postulaba correspondencias entre planos sociológicos y biológicos como dimensiones de la vida humana estrechamente ligadas y codependientes. Esa idea fue defendida como «verdad científica» bajo la égida del determinismo biológico, y aún hoy goza de cierta legitimidad en la nueva y no tan nueva derecha ${ }^{13}$. En la medida que este control sociobiológico se extendía a grupos de poblaciones e individuos determinados, dispuestos a la mejora (o eliminación), la idea de una naturaleza humana «fija» e «inmutable» independiente de sus particularidades teóricas siguió siendo uno de los dogmas centrales de toda aplicación eugenésica. La filosofía detrás de estos verdaderos intentos de selección, domesticación y cultivo de esta «naturaleza humana» revela la paradoja inscrita en la relación entre esta y su auto transformación mediante los dispositivos eugenésicos. Porque el problema más bien parece ser, que a pesar de las políticas de esterilización forzosa en EE.UU. a principios de siglo XX (Hubbard y Wald, 1999) o los programas de eugenesia e higiene racial durante el régimen nazi (Hubbard y Wald, 1999), la

12 Para una discusión sobre estos temas, véanse los trabajos de Michel Foucault sobre biopoder y la incidencia del Estado como biopoder y biopolítica (2006; 2008), así como también los trabajos del filósofo italiano Roberto Esposito (2006; 2009).

13 Para una profundización de esta discusión, véase los trabajos del antropólogo y biólogo, Ashley Montagu (1941; 1942), además de una profunda problematización del determinismo biológico por Lewontin, Rose y Kamin (1987). 
concepción de ser humano ya ahí enraizada no sufrió mayores transformaciones - a pesar de la declaración universal de DD.HH.—, manteniéndose en la línea sociobiológica que la hizo posible.

A pesar de la historia quizás más cruenta de las manipulaciones humanas que significó la eugenesia, hoy las condiciones de posibilidad hacia una efectiva autotransformación tecnológica de seres humanos cada vez más óptima están dadas. Pero la persistencia de estos temas y debates dan cuenta de la naturaleza compleja no solo de la eugenesia como «ideología sociobiológica» en sí, sino a modo más general, de la transformación de la vida a través de la tecnológica ${ }^{14}$. Esto nos puede llevar a dos hipótesis que pueden desembocar en dos puntos de vista diversos acerca de los procesos de autotransformación del ser humano:

1. La eugenesia como proyecto tecnológico estaba destinada al fracaso debido a su concepción de ser humano anclada en su ideal sociobiológico. Esta hipótesis debiera proponer un análisis histórico que se refiere a la relación entre una interpretación biológica de ser humano que de esta forma aúne las disposiciones individuales de adaptación (biológicas, fisiológicas, psicológicas), en relación, a su vez, con los dispositivos tecnológicos de control y disciplinamiento. En este sentido, la visión del mundo desde «la raza», de la cual la propia eugenesia nutría sus componentes ideológicos y científicos, sufría de una estrechez de comprensión, a pesar de su violenta capacidad de romper todo límite entre bios y zoe, entre lo humano y lo anima $1^{15}$. Capacidad a la vez impulsada por la puesta en marcha de una pretensión de control del cuerpo humano y su descendencia, su vaivén paradojal entre una biopolítica afirmativa y una tanatopolítica destructora de toda

14 Sin tomar en cuenta las transformaciones de las subjetividades humanas a partir de los dispositivos tecnológicos, donde hoy en día resultaría difícil pensar siquiera al ser humano «moderno» sin los aparatos que lo complementan y que en gran parte configuran su subjetividad postmoderna. Al respecto son notoriamente interesantes las reflexiones, en el ámbito de la ciencia y la tecnología, de autores como Latour y Serres, para quienes - y ambos comparten este mismo principio - la subjetividad humana, sobre todo desde sus procesos cognitivos, se encuentra inexorablemente anclada en los objetos (que en terminología de ambos autores no funcionan como simples «objetos» inertes y pasivos), y por ello el ser humano se ha ido perfilando en la práctica en un ente híbrido, que deambula — sin sospecharlo - entre las aguas de la cultura y la naturaleza.

15 Los trabajos en el campo de la biopolítica, sobre todo en su vertiente italiana, con Agamben y Esposito resultan ser esclarecedores sobre esta temática que gira en torno a la animalidad del ser humano y los límites — no tan precisos - en uno y otro, difuminados sobre todo en las experiencias totalitarias del siglo XX. Véanse por ejemplo los trabajos de Agamben sobre los musulmanes (Agamben, 2006; 2009) Véase también La filosofia animal de Nietzsche. Cultura, política y animalidad del ser humano, de V. Lemm. 
vida (Esposito, 2006; 2009) A pesar de todo eso, los portavoces de la eugenesia no fueron capaces de estimar el potencial transformador de la tecnología humana aplicada a su propio cuerpo-mente-inteligencia, lo que los llevó a primar la visión racial sobre las posibilidades de mejora por vía tecnológica. Como resultado se dio una visión miope que no lograba acceder comprensivamente a la paradoja inscrita en este programa político-tecnológico. Más allá de los límites de la concepción racial, que a pesar de su «fijismo» exacerbado, proclamado como ordenamiento sociobiológico de las diferencias humanas, pretendía la transformación de esa «naturaleza humana» que al menos en teoría no se comprendía sujeta a procesos de transformación. En este sentido, históricamente se revela la paradoja de que la eugenesia alberga en su núcleo y que hoy vuelve sobre él, a raíz de las persistentes transformaciones que hoy la tecnología proyecta sobre el ser humano, su constitución genética y orgánica ${ }^{16}$.

2. Una hipótesis en términos de una filosofía de la tecnología, que refiere a que los dispositivos tecnológicos continuamente tenderán a romper/estallar los límites de la «esfera humana» provocando su eventual crisis de sentido. Esta hipótesis estima la cuasi imposibilidad de conciliar el desarrollo tecnológico, sea cual sea e independientemente de su expresión, con cierta definición precisa de ser humano. Llegado cierto límite, el que aquí podemos denominar sociobiopolítico, la tecnología tenderá a romper toda presuposición ontológica de ser humano, haciendo así cada vez más visible su indistinción. Volviendo al caso de la eugenesia, el camino recorrido desde las primitivas formas de esterilización forzosa, hasta los actuales inventos en robótica y nanotecnología, no solo reconfiguran nuestra relación con un medio cada vez más tecnificado, sino que nos ponen en alerta que estamos efectivamente ante un inmenso desafío de repensar nuestra naturaleza, si es que la hay (Bayertz, 2009). En este sentido, la tecnología remite cada vez más a esa «zona gris» de indistinción que constituye la definición que nos hemos hecho y hacemos del «ser humano» ${ }^{17}$ (Agamben, 2006).

16 La crudeza de este argumento finalmente arguye que el recorrido final de toda política racista es el exterminio y no la eugenesia.

17 Un argumento muy similar desarrolla el filósofo español Jesús Hernández, en relación con la biopolítica y el poder de la biotecnología. La tesis central del autor sostiene en clave biopolítica, la biotecnología significa un poder sin igual sobre la vida humana y que no tiene límites más de lo que considera posible o no posible de hacer y transformar. En palabras del autor: «Por consiguiente, es una forma de racionalidad, es un modo de poder sobre la vida. Y su peculiaridad consiste en ser la máxima expresión de una cultura capaz de albergar en su seno la más variada diversidad, hasta el punto de poderse sospechar que nada queda fuera de su dominio. Complementando la visión que toma sus logros como objetos de debate ideológico 
Nos encontramos ante la encrucijada del desarrollo de tecnologías que hoy reconfiguran no solo nuestro entendimiento de un límite preciso entre lo (im) posible y lo (im)probable. Lo primero no tanto en términos de «posibilidad de hacer», sino más bien en cuanto a la fluctuación de las normas, llámese morales, éticas y jurídicas, que las posibilitan. Y lo segundo, en cuanto a la apertura y aparición de nuevas configuraciones sujeto-objeto, naturaleza-cultura, y otras ontologías (Escobar, 2009) que ponen en entredicho nuestra comprensión de los hechos debido a cierta «falta de lenguaje» que nos permita abordarlas comprensivamente (Beck, 2017). En pocas palabras, la aparición de lo «(im)probable» demuestra, en ocasiones, que la realidad nos supera.

En gran parte, estas transformaciones ocurren en el plano del quehacer tecnocientífico, que tiende a sobrepasar los límites éticos y morales sin mayores frenos que los jurídicos. Es decir, lo que es posible dentro del campo de aplicación, manipulación y transformación tecnocientífica, parece, a la vez, permitido. Esta idea, un tanto polémica, no intenta pasar por alto las discusiones del campo de la bioética con relación a la práctica médica, sino más bien, apuntar al efecto inevitable de un desarrollo y una emergencia del carácter híbrido de las prácticas humanas y de la fluctuante normativa que acompaña estos procesos en vistas a su potencial médico y eugenésico.

Estamos ante la incertidumbre de una serie de definiciones y conceptualizaciones que parecen obsoletas a la hora de definir lo que a partir de ello enteremos por «ser humano» y «naturaleza» (Sibilia, 2009; Cornejo, 2017b). Ambas categorías hoy parecen insostenibles y lo que aparece en lugar de ellas merece tanto aclaraciones conceptuales, como nuevos debates que giren en torno a estas nuevas valoraciones teóricas. Tales caminos ya se han emprendido con frecuencia, pero siguen siendo — por una razón quizás entendible —, marginales dentro de la teoría social debido a su carácter complejo, $\mathrm{y}$, a veces confuso.

o técnico, la aproximación a la biotecnología a través de su consideración como poder nos muestra su entronque en una vida humana que ha llegado a ser capaz de encontrar modelable a su gusto la totalidad de lo que existe, incluido al hombre mismo [...] el hombre como material de construcción y el hombre como resultado son elementos de una misma racionalidad» (Hernández, 2005, p. 39). 


\section{EL NUEVO PROYECTO TECNOLÓGICO DE LA EUGENESIA LIBERAL: ENTRE LA LIBERTAD Y LA RESPONSABILIDAD EN EL CASO DEL WRONGFUL BIRTH Y WRONGFUL LIFE}

La reaparición de la eugenesia como problemática la debemos entender anclada en el desarrollo biotecnológico y la ingeniería genética aplicada al «parque humano», sobre todo por la emergencia de las ciencias de la vida (life science) en el campo de la medicina y la medicina reproductiva, tales como la terapia génica, la fertilización in vitro, el diagnóstico prenatal y el tamizaje genético. Técnicas que comparten una visión optimista del desarrollo tecnológico en vistas a la mejora de la salud genética no de grupos o poblaciones enteras, sino de individuos discretos, los cuales en su calidad de entes racionales disponen de las facultades individuales de determinar una posible aplicación biotecnológica en su descendencia (Rifkin, 1999; Testart y Godin, 2002). Por otra parte, su apellido discutido de «liberal» remite a su carácter de mercancía y la existencia de un mercado de salud y planificación familiar en el cual estas intervenciones se ofrecen como parte de un stock de ofertas (Speck, 2005). Esto implica una simetría creciente entre la «liberalización» del individuo o los futuros padres y madres, de elegir entre una vasta gama de elementos socioculturales y tecnológicos (educación, intervención genética, salud, herencia, planificación familiar) que favorezcan el futuro de sus hijos (sin duda determinados por el acceso de estos «recursos») y la exigencia de responsabilidad que acompañan dichas elecciones.

La tecnología genética conlleva la ampliación de la libertad del ser humano, es decir, el ejercicio de la decisión que también puede afectar a terceros, en este caso, nonatos. Por lo tanto, la libertad, entendida aquí como "poder de decisión», se extiende hacia nuevos ámbitos. Ante el problema que suscita la decisión en nombre de nonatos, consiste la crítica de Habermas ante la posibilidad de que padres dicten la salud genética de sus hijos por nacer. Según el filósofo alemán, estos niños - intervenidos mediante selección o terapia génica — no habrán sido tratados como un fin en sí mismo, sino como medios para la satisfacción de deseos de terceros (Habermas, 2002). Claramente, que para la filosofía kantiana — base en el argumento de Habermas-, implica un atentado a la libertad individual de los niños que aún no han nacido, pero que sin importar su voluntad han sido ya objeto de intervención tecnológica, por lo tanto, la esfera de su propia libertad — «libertad» entendida aquí como «autodeterminación»— habrá sido violada en el acto mismo de la intervención para satisfacer los fines de otros (Pallares y Chiva, 2016). 
Lo que se enfrenta aquí son dos «libertades»: la libertad de elección de los padres, en usufructo de la tecnología genética y la libertad menguada del nonato sin posibilidad de elegir y, por tanto, ente pasivo de cualquier tipo de intervención en su genoma. Esta doble cara de la libertad nos plantea la cuestión paradojal entre el ámbito de la decisión y el ejercicio de la libertad de los padres (por ejemplo, de «elegir» características deseadas mediante modificación genética) y la consecuente disminución del espacio de libertad de aquellos niños intervenidos genéticamente. Esta problemática implica la apertura hacia un espacio ontológico de la planificación de un «futuro posible» y es quizás uno de los ejes más problemáticos de la eugenesia liberal, ya que, a su vez, implica la profunda estrechez con otros fenómenos asociados a ella, tal como el aborto eugenésico.

La pregunta ontológica que define un campo de intervención o de decisión sobre algo que aún no es — pero que probablemente será - acarrea de esta forma tanto el orden jurídico como el filosófico. Siendo que el orden filosófico es abordado por diversos autores - la mayoría reacios o al menos sospechosos de tales intervenciones-, pero que a fin de cuentas buscan establecer criterios definidos de aplicabilidad e intervención humana en un sentido más bien normativo (Jonas, 1984; Buchanan y otros, 2000; Habermas, 2002); mientras que el orden jurídico puede ser entendido como el punto de anclaje de la experiencia humana en estos ámbitos, es decir, su expresión propiamente empírica. Simplificando, se puede argumentar que, mientras que los juicios filosóficos implican consideraciones bioéticas sobre la norma y ética humana — es decir, lo que el ser humano debe o no hacer sin incurrir en violaciones de sus propias reglas de convivencia-, la dimensión jurídica, a pesar de moverse justamente en esa misma esfera, a su vez, da cuenta de lo «ya realizable» con respecto a violaciones de una ley ya definida, es decir, del espacio de apertura de la intervención tecnológica sobre la vida y las consideraciones sobre esta vida que emergen a raíz de ella.

Si la ontología nos permite interrogar el significado de la existencia de nuevos seres humanos y no-humanos, nuevas entidades híbridas, tecnológicas, confusas, los que emergen a raíz de las disposiciones tecnológicas y configuraciones entre naturaleza y cultura, esta también debe implicar el problema de la autoconciencia del ser humano respecto a ellas (Habermas, 2002), sobre todo ante un «determinismo tecnológico» que a pesar de todas las dudas, tiende a lidiar continuamente con la ética médica incorporándola en sus designios. Como ya señalamos anteriormente, el límite a la performance tecnológica está configurado a partir de las posibilidades reales y materiales de acción (su dimensión tecnológica), la reflexión acerca de la permisibilidad (la discusión bioética) y su 
normatividad jurídica (restricciones legales). Ahí es donde los sistemas jurídicos dan claros indicios de esta problemática a partir de casos empíricos, sobre todo en aquellos países donde la eugenesia liberal ${ }^{18}$ es parte integral ya de los presupuestos de salud y bienestar físicos-mentales de carácter hipotético amparada en esta filosofía de la planificación.

La apertura de la esfera legal hacia estas concepciones, claramente ligada al juego de apertura y clausura del ámbito de la libertad de acción mediante el diagnóstico prenatal y el diagnóstico preimplantacional, vuelven posibles ciertos grados de selección del feto y la eventual eliminación vía aborto legalizado una vez detectada alguna anomalía cromosómica. Sin duda existe la tendencia creciente de abortar aquellos fetos con malformaciones congénitas para evitar el nacimiento de niños con discapacidades ya diagnosticadas genéticamente. A raíz de eso, en la esfera del derecho civil, esto ya se ha implantado como una problemática de complejidad, sobre el reclamo por perjuicio y daño que un nacimiento de esa envergadura significa hoy en día ${ }^{19}$. Por tanto, es sintomática la aparición de discusiones de orden jurídico, sobre percepciones de perjuicio y riesgo, como es el caso de wrongful birth y wrongful life $e^{20}$, experimentado ya en diversas partes del mundo. Más allá de la discusión que atañen las ciencias jurídicas, así como de la administración pública, la pregunta axiológica da en el meollo de la cuestión que acarrea la libertad de los sujetos posmodernos en su libre autodeterminación ${ }^{21}$. La aparición de estas categorías surge en la medida en que avanzan las facultades tecnológicas de diagnóstico prenatal y suele estar

18 La utilización de este término obedece en parte a la usada por Habermas, en vista a la diferencia entre una eugenesia estatal y una eugenesia liberal, que, a diferencia de la primera, pone en el centro de la acción eugénica no a la acción y planificación biopolítica del Estado hacia una población determinada (judíos, gitanos, homosexuales, etcétera), sino al individuo como consumidor, en cuanto a sus decisiones de reproducción, cuidado de sí, alimentación, vida sana, etc. Sin duda imperativos posmodernos de nuevas formas de vida y de enfrentar la vida desde el cuidado del cuerpo y no sin cierta autoconciencia corporal. Así también se entiende que la eugenesia liberal no obedece a la acción concertada de un Estado enfocado al control disciplinario de los cuerpos (Foucault), sino más a fragmentos de discursos dispersos que versan sobre la salud y el bienestar individual.

19 Marcia Murillo señala que desde el siglo XX han ido surgiendo diversas formas de entender el daño, ampliándose así la esfera de las posibilidades jurídicas de reclamación de daño.

20 Ambas surgidas en EE.UU. durante la segunda mitad del siglo XX, con el caso Gleitman vs. Cosgrove en 1967 y Jacobs vs. Theimer en 1975.

21 En Chile hemos sido testigos de la fuerte resistencia de los poderes eclesiásticos en aceptar la libre determinación de la mujer de disponer de su propio cuerpo y solo en el caso de causales bien definidas y delimitadas. En este sentido, la libertad de la mujer sigue siendo enclaustrada por el lobby de las iglesias, tanto católica como evangélica. 
asociada, además, a normativas jurídicas que permitan la interrupción del embarazo según criterios definidos.

Ello implica la paradojal situación de un derecho extendido hacia una vida «potencial», con lo cual la política del riesgo se extiende hacia el ejercicio médico y su esfera de responsabilidad, es decir, el diagnóstico correcto y el consejo apropiado ante una situación de hipotética enfermedad del feto. Asimismo, involucra la responsabilidad de los padres ante la decisión «correcta» de seguir o interrumpir el ciclo de embarazo — dentro del plazo jurídicamente estipulado-, cuando existan evidencias de futuros riesgos. Así, el sentido de responsabilidad se extiende hacia ambos campos: la situación parental y el rol del médico, teniendo presente que cualquier decisión que se tome al respecto puede acarrear un futuro conflicto jurídico. Por ello, estas demandas suelen responsabilizar tanto a los médicos en su rol de consejeros ${ }^{22}$ como a los padres respecto de su decisión de seguir adelante un embarazo de tal índole.

Mientras que wrongful birth es una demanda interpuesta por los padres hacia el médico o las instituciones médicas en reclamación de daños y perjuicios causados por un «falso negativo» del diagnóstico, es decir, el error en la entrega de información o su eventual ausencia, la acción de wrongful life se refiere a la demanda interpuesta por el propio niño en reclamación por el perjuicio causado a su propia persona por el hecho de haber nacido en tales condiciones. Ambas presuponen un argumento que apunta hacia una evidente «equivocación» al no recurrir al aborto

22 Una cita de Marcia Morillo muestra con claridad la situación a veces compleja en la cual se encuentran los propios doctores ante estos escenarios: «A partir de este salto, y ante la dificultad intrínseca a la reclamación de una responsabilidad frente a los progenitores en este contexto, la atención en estos supuestos de nacimiento de niños que padecen de ciertas enfermedades graves e incurables se pasa a centrar sobre los profesionales sanitarios. Y es que, en los últimos años, estos profesionales se han visto sometidos progresivamente a un - llamémoslo así- «acoso», desconocido hasta hace relativamente poco. Por un cúmulo de factores - entre los que se cuentan los avances en la medicina que han permitido retrasar o evitar la mortalidad humana en relación en un amplio número de enfermedades, la vulgarización de los conocimientos médicos o el mayor número de obligaciones asumidas por los profesionales sanitarios [...] - se ha perdido el temor reverencial al médico, y este ha pasado a ser objeto de sospecha y de reclamación cuando no se alcanza la curación que persigue todo paciente. Con ello, actualmente, cuando el resultado favorable o sanador no se produce, es al médico y no a la Naturaleza a quien considera responsable el paciente, y a quien le exige la reparación del daño experimentado» (Murillo, 2007, p. 12). Más adelante, refiriéndose a ambos tipos de demandas dice sobre la supuesta negligencia del médico: «en ninguna de estas reclamaciones se alega que el profesional sanitario causara el mal que sufre el niño, sino que no advirtió de él a sus progenitores y que, por ello, no se pudo impedir el nacimiento del niño enfermo» (Murillo, 2007, p. 20). 
en el plazo legalmente estipulado, debido a la entrega de información «errónea» sobre las condiciones de salud genética del futuro bebé o la decisión equivocada de los padres. Para su análisis, los juristas deben intentar separar conceptualmente el daño causado, la vida enferma, el error en o la ausencia de información y la (im)posibilidad de ejercer el derecho de los padres de interrumpir el embarazo dentro del plazo legal (Morillo, 2007).

Como ya se ha señalado, la acción wrongful birth aboga por el derecho de los padres o la gestante que por negligencia médica no pudieron decidir adecuadamente si proseguir o no con el embarazo, debido a una evidente falta de información sobre el estado del feto; wrongful life en cambio, implicaría una mayor carga «simbólica» debido que la demanda se hace en nombre del niño o la niña que ha nacido con algún tipo de discapacidad y que le significa graves perjuicios morales y económicos, pero argumentando que la negligencia no solo produjo la enfermedad sufrida, sino más bien su nacimiento.

Este fenómeno de envergadura nos sitúa en el campo de la discusión biopolítica sobre la vida nuda en el sentido de Agamben o la vida en potencia en el sentido de Esposito o Deleuze, ya que a partir de esta visión es la propia vida que, en su definición relativa a la salud y enfermedad, es entendida como daño. Pero lo sorprendente es que, a diferencia de la experiencia totalitaria del siglo $\mathrm{XX}$, la valoración de esta vida no es definida «desde fuera», por ejemplo, desde un estado totalitario, como en el caso del Lebensunwertes Leben ${ }^{23}$ nacionalsocialista, sino que es el propio sujeto que apela a esta autoevaluación, es decir que, en su facultad y autoconciencia se siente y entiende como tal: vida equivocada.

Esto además atañe la política pública sobre la discapacidad y la visión de la sociedad en cómo enfrentar la vida de y con los discapacitados ${ }^{24}$. Un nacimiento así, vista desde la crudeza del argumento jurídico, debe entenderse como una

\footnotetext{
23 Expresión alemana para «vida carente de valor».
}

24 Como señala un abogado español, estudioso de estas demandas, con relación a la situación de la discapacidad que de estas acciones emergen: «El diagnóstico, confirmado por un comité clínico, posibilita el aborto de fetos cercanos al nacimiento a término, que podrían vivir de modo independiente de la madre inmediatamente. Como es obvio, se está configurando un tratamiento legal excepcional y mucho menos favorable para los fetos con "graves anomalías" o con enfermedades "extremadamente graves e incurables". Su dignidad, precisamente por su discapacidad, no se respeta de modo adecuado, pues en vez de promover medidas para favorecer su integración en la sociedad se dan mayores facilidades para su eliminación, como algo indeseable. De modo implícito se considera de distinto valor la vida en función de la capacidad o discapacidad» (Torre de Silva, 2017, p. 128). 
consecuencia fatal de una mala práctica médica o de una decisión errónea de los gestores, pero en ambos casos prevalece el argumento de la vida como error.

La afirmación de la responsabilidad parece chocar frontalmente con la idea de la vida como bien más preciado del ser humano y con la dignidad de la persona, que se pone en cuestión en el momento en que se afirma su propia existencia como daño (...) La solución pasa por separar (doctrina alemana de la separación: Trennungslehre) el daño reclamado de la vida del hijo, centrando aquél, bien en la lesión de la libertad de procreación que se reconoce a todo sujeto [...[ bien en la facultad de la madre de interrumpir voluntariamente el embarazo, bien en los gastos que acarrea el niño (carga suplementaria que para los padres representará su sostenimiento y educación) —que son distintos a su vida— (Pacheco-Jiménez, 2011, pp. 7-8).

Es de entender así que la aplicabilidad del aborto eugenésico, sobre todo en vista al potencial futuro del feto en cuestión, implica por tanto una serie de cálculos que se escapan de aquellos específicamente médicos. La salud implica, bajo estos términos, una categoría que integra sobre todo cálculos sociales y morales: salud y bienestar, libertad de decisión y autonomía, y que se mezclan en un horizonte biopolítico que debe atender a los nuevos imperativos posmodernos de libertad humana, así como los cálculos que imperan en todo acto de nacimiento y las preguntas que de ello emergen: ¿cuál va a ser la calidad de vida del niño o la niña enferma? ¿Cómo se verá afectada la familia, en términos morales y económicos si es que decide llevar adelante la vida de esta persona? (Cornejo, 2017a). Por ello, la entrada de una eugenesia liberal asociada a un cálculo social, económico y moral implica, a su vez, un orden de creciente reflexibilidad de lo que significa nacer y vivir en un mundo donde las facultades individuales, sobre todo referentes a la salud, son determinantes a la hora de desarrollar un capital humano de acuerdo con los imperativos sociales de la competitividad vivida bajo el neoliberalismo (Vázquez, 2005; Rose, 2007; Foucault, 2008.). Bajo esta perspectiva, «la salud» ya deja de ser un concepto específicamente médico centrado únicamente en las disposiciones biológicas o mentales de un individuo o (grupos de individuos-población), para extender sus significados hacia otras esferas: esto se refleja en la creciente exigencia del cuidado, cultivo-domesticación y planificación que posibilita la intromisión técnica en los cuerpos humanos y las evidentes conflictividades que emergen a raíz de nuevos dispositivos jurídicos que reclaman nuevos derechos a partir de determinaciones emergentes sobre vida humana, salud y enfermedad. 


\section{PALABRAS FINALES}

El horizonte biopolítico tiende continuamente a resignificar la vida humana en función de los nuevos requerimientos tecnológicos que implican a su vez nuevas intervenciones en los cuerpos biológicos. La vida no solo es objeto de la política y de una tecnología cada vez más invasiva, sino que, parafraseando a Donna Haraway, es continuamente creada por ambas esferas cada vez más difíciles de distinguir. Despojada esta vida de su sustrato natural, las tecnociencias tienden a romper continuamente las ontologías basadas en lo orgánico, aunque como sugieren ya diversos investigadores este supuesto carácter «natural» de la vida orgánica siempre ha sido más bien una ilusión moderna, que, con el advenimiento de una tecnología domesticadora de los procesos humanos, evidencia su carácter híbrido y paradojal (Latour, 2007; Escobar, 2009). En palabras de Escobar, nos enfrentamos así a una naturaleza tecnológica, caracterizada por la hibridez de sus procedimientos, abierta a la domesticación del ser humano mediante la tecnología humana. Ello también requiere la urgente pregunta por una «naturaleza humana» despojada del supuesto carácter fijo de nuestra constitución, abierta a la continua transformación y a una vorágine llena de incertidumbres.

\section{REFERENCIAS}

Agamben, Giorgio (2006). Lo abierto. Buenos Aires: Adriana Hidalgo Editora S.A.

Agamben, Giorgio (2009). Lo que queda de Auschwitz. El archivo y el Testigo. Homo sacer III. Valencia: Pre-Textos.

Bayertz, Kurt (2009). Hat der Mensch eine «Natur»? Und ist sie wertvoll? En M. G. Weiß, Bios und Zoe. Die Menschliche Natur im Zeitalter ihrer technischen Reproduzierbarkeit (pp. 191-218). Frankfurt am Main: Suhrkamp.

Beck, Ulrich (1998). La politica de la sociedad de riesgo. Estudios demográficos y urbanos, 13(3), 501.

Beck, Ulrich (2017). Die Metamorphose der Welt. Berlín: Suhrkamp.

Buchanan, Allen, Dan W. Brock, Norman Daniels y Daniel Wikler (2000). From Chance to Choice. Genetics and Justice. Cambridge: Cambridge University Press.

Castells, Manuel (2001). La era de la información. Economía, sociedad y cultura. El poder de la identidad Vol. II. México, D. F.: Siglo XXI.

Cornejo, Sascha (2017a). Políticas de la especie. Eugenesia, vida e ingeniería genética. Santiago de Chile: Ril. 
Cornejo, Sascha (2017b). La relación naturaleza y ser humano, tecnología y biología bajo la luz del posthumanismo. Revista Antropologías del Sur (UAHC), 4(8), 215-232.

Descola, Philippe (2004). Die Ökologie der Anderen. Berlín: Matthes \& Seitz.

Descola, Philippe y Gísli Pálson (2001). Naturaleza y sociedad. Perspectivas antropológicas. México, D. F.: Siglo XXI.

Escobar, Arturo (2009). El final del salvaje. Naturaleza, cultura y politica en la antropología contemporánea. Santa Fé de Bogotá: CEREC.

Esposito, Roberto (2006). Bios. Biopolítica y filosofía. Buenos Aires: Amorrortu.

Esposito, Roberto (2009). Comunidad, inmunidad y biopolitica. Barcelona: Herder.

Foucault, Michel (1996). Genealogía del racismo. La Plata: Altamira.

Foucault, Michel (2006) Seguridad, territorio y población. Curso del College de France (1977-1978). México, D. F.: F.C.E.

Foucault, Michel (2008). Nacimiento de la biopolítica. Buenos Aires: F.C.E.

Habermas, Jürgen (1997). Ciencia y técnica como ideología. Madrid: Tecnos.

Habermas, Jürgen (2002). El futuro de la naturaleza humana. ¿Hacia una eugenesia liberal? Barcelona: Paidós.

Hernández Reynés, Jesús (2005). El poder sobre la vida» formas biopolíticas de la racionalidad. En Javier Ugarte Pérez (comp.), La administración de la vida. Estudios biopoliticos (pp. 13-43). Barcelona: Anthropos.

Hohlfeld, Rainer (2000). Das Zeitalter von Genomics. Zur politischen Okonomie der Molekularen Medizin. En C. Muerner, A. Schmietz y U. Sierck, Schöne heile Welt? (pp. 31-45). Hamburg/Berlin: Libertäre Assoziation/Schwarze Risse/Rote Strasse.

Hubbard, Ruth y Elijah Wald (1999). El mito del gen. Madrid: Alianza.

Jonas, Hans (1984). Das Prinzip Verantwortung. Versuch einer Ethik für die technologische Zivilisation. Frankfurt am Main: Suhrkamp.

Latour, Bruno (1998). La tecnología es la sociedad hecha para que dure. En M. Doménech y F. J. Tirado, Sociología simétrica. Ensayos sobre ciencia, tecnología y sociedad. Barcelona: Gedisa.

Latour, Bruno (2001). La esperanza de Pandora. Ensayos sobre la realidad de los estudios de la ciencia. Barcelona: Gedisa.

Latour, Bruno (2005). Llamada a revisión de la modernidad. Aproximaciones antropológicas. Revista Antropológica Iberoamericana. 
Latour, Bruno (2007). Nunca fuimos modernos. Ensayo de antropología simétrica. Buenos Aires: Siglo XXI.

Lemm, Vanessa (2010). La filosofía animal de Nietzsche. Cultura, politica, y animalidad del ser humano. Santiago de Chile: UDP.

Lewontin Richard C., Steven Rose y Leon J. Kamin (1987). No está en los genes. Racismo, genética e ideología. Barcelona: Crítica.

Leyton, César, Cristián Palacios y Marcelo Sánchez (eds.) (2015). El bulevar de los pobres. Racismo científico, higiene y eugenesia en Chile e Iberoamérica, siglos $X I X$ y $X X$. Santiago de Chile: Ocho libros.

Macía Morillo, Andrea (2007). La responsabilidad civil médica. Las llamadas acciones de Wrongful Birth y Wrongful Life. Revista de Derecho, (27), 3-37.

Marcuse, Herbert (1970). El hombre unidimensional. Barcelona: Seix Barral.

Montagu, M. F. Ashley (1941). The Biologist Looks at Crime. Anals of the American Academy of Political and Social Science. Philadelphia, U.S.A. September. https://doi.org/10.1177/000271624121700107

Montagu, M. F. Ashley (1942). The nature of war and the myth of nature. The Scientific Monthly, LIV, 342-353.

Pacheco-Jiménez, María Nieves (2011). Acciones Wrongful Birth y Wrongful life: una controversia vía de responsabilidad civil médica. Documento de trabajo. Seminario Permanente de Ciencias Sociales (pp. 1-16). Cuenca: Facultad de Ciencias Sociales de Cuenca. Recuperado de https://www.uclm.es/-/media/Files/ C01-Centros/cu-csociales/documentos2011/2-2011.ashx?la=es

Pallares, Marc y Oscar Chiva (2016). Jürgen Habermas y el riesgo de la eugenesia liberal para la autocomprension ética de la especie. Argumentos de Razón Técnica, (19), 105-122. https://doi.org/10.12795/Argumentos/2016.i19.06

Rifkin, Jeremy (1999). El siglo de la biotecnología. Barcelona: Crítica.

Rose, Nikolas (2007). The politics of life itself: Biomedicine, power and subjectivity in the twenty-first century. Princeton: Princeton University Press. https://doi. org/10.1515/9781400827503

Sibilia, Paula (2009). El hombre postorgánico. Cuerpo, subjetividad y tecnologías digitales. Buenos Aires: FCE.

Sloterdijk, Peter (2006). Normas para el parque humano. Madrid: Siruela.

Sloterdijk, Peter (2012). Has de cambiar tu vida. Valencia: Pre-Textos.

Speck, Otto (2005). Soll der Mensch biotechnisch machbar werden?. Eugenik, behinderung und padagogik. Múnich: Ernst Reinhard Verlag. https://doi. org/10.2378/9783497017874 
Testart, Jacques y Christian Godin (2002). El racismo del gen. Biología, medicina y bioética bajo la férula liberal. Buenos Aires: FCE.

Torre de Silva López de Letona, Víctor (2017). Responsabilidad por nacimiento evitable (wrongful birth) y discapacidad. Revista de Administración Pública, (203), 89-136. https://doi.org/10.18042/cepc/rap.203.03

Vázquez García, Francisco (2005). Empresario de nosotros mismos. Biopolítica, mercado y soberanía en la gubernamentabilidad neoliberal. En J. Ugarte (comp.), La administración de la vida. Estudios biopolíticos (pp. 73-103). Barcelona: Anthropos.

Weingart, Peter, Jürgen Kroll y Kurt Bayertz (1992). Rasse, Blut und Gene. Geschichte der Eugenik und Rassenhygiene in Deutschland. Fráncfort del Meno: Suhrkamp. 